\title{
Teknik Dan Bentuk Evaluasi Hasil Belajar
}

Hasim Hasim $^{1}$, Hasniah Hasniah ${ }^{2}$, Muhammad Arsyam ${ }^{3}$

${ }^{1}$ Sekolah Tinggi Agama Islam (STAI) Darul Dakwah Wal-Irsyad (DDI) Kota Makassar, Indonesia Email: hasimnak164@gmail.com

${ }^{2}$ Sekolah Tinggi Agama Islam (STAI) Darul Dakwah Wal-Irsyad (DDI) Kota Makassar, Indonesia Email: akhwathasniah@gmail.com

${ }^{3}$ Sekolah Tinggi Agama Islam (STAI) Darul Dakwah Wal-Irsyad (DDI) Kota Makassar, Indonesia

Email: arsyam0505@gmail.com

\begin{abstract}
Abstrak
Teknik evaluasi adalah metode yang digunakan agar suatu tujuan evaluasi, yaitu menggali informasi tentang peserta didik dapat tercapai. Untuk melakukan evaluasi maka evaluator harus menguasai teknik evaluasi. Dengan penilaian guru akan mengetahui perkembangan hasil belajar, intelegensi, bakat khusus, minat, hubungan sosial, sikap dan kepribadian siswa atau peserta didik. Untuk keperluan evaluasi diperlukan teknik evaluasi yang bermacam-macam, seperti kuesioner, tes, skala, format observasi, dan lain-lain. Dari sekian banyak teknik evaluasi, secara umum dapat dikelompokkan menjadi dua, yakni teknik tes dan nontes. Khusus untuk evaluasi hasil pembelajaran teknik evaluasi yang paling banyak digunakan adalah tes.
\end{abstract}

\section{Kata Kunci: Teknik, Evaluasi, Hasil Belajar}

\section{A. Pendahuluan}

Seiring dengan perkembangan jaman, pendidikan dituntut untuk dapat mencetak insan yang bermartabat dan berkualitas agar dapat meningaktkan taraf hidup bangsa. Berbagai perubahan telah dilakukan dalam dunia pendidikan untuk memenuhi kebutuhan sesuai dengan tuntutan zaman. Untuk mengetahui apakah pendidikan yang telah dilaksana sudah dapat menghasilkan lulusan yang berkualitas, maka perlu diadakanya suatu evaluasi dalam pendidikan.

Teknik evaluasi adalah metode yang digunakan agar suatu tujuan evaluasi, yaitu menggali informasi tentang peserta didik dapat tercapai. Untuk melakukan evaluasi maka evaluator harus menguasai teknik evaluasi. Dengan penilaian guru akan mengetahui perkembangan hasil belajar, intelegensi, bakat khusus, minat, hubungan sosial, sikap dan kepribadian siswa atau peserta didik. Untuk keperluan evaluasi diperlukan teknik evaluasi yang bermacam-macam, seperti kuesioner, tes, skala, format observasi, dan lain-lain. Dari sekian banyak teknik evaluasi, secara umum dapat dikelompokkan menjadi dua, yakni teknik tes dan nontes. Khusus untuk evaluasi hasil pembelajaran teknik evaluasi yang paling banyak digunakan adalah tes. Untuk melakukan evaluasi maka evaluator harus menguasai teknik evaluasi. Teknik evaluasi adalah metode yang digunakan agar suatu tujuan evaluasi, yaitu menggali informasi tentang peserta didik dapat tercapai. Ada dua macam teknik evaluasi yang dapat digunakan dalam melaksanakan evaluasi, yaitu teknik non tes dan teknik tes. 


\section{B. PEMBAHASAN}

\section{Bentuk evaluasi hasil belajar}

Secara garis besar ada dua macam bentuk penilaian, yaitu bentuk tes subjektif dan bentuk tes objektif. Berikut penjelasannya:

\section{1) Tes Subjektif}

Tes subjektif ini biasa disebut juga sebagai tes essay atau essay examination. Yang dimaksud dengan tes essay adalah tes yang berbentuk pertanyaan tulisan, yang jawabannya merupakan karangan (essay) atau kalimat yang panjang-panjang. Tes esai merupakan bentuk penilaian yang paling dikenal dan banyak digunakan oleh guru-guru disekolah dari dulu sampai sekarang. Umumnya tes esai ini berjumlahkan lima sampai sepuluh item soal saja.

Menurut sejarah yang ada lebih dahulu itu adalah bentuk tes subjektif ini / tes esai. Akan tetapi karena bentuk ini banyak kelemahan-kelemahan, maka para ahli pendidikan berusaha untuk menyusun tes dalam bentuk yang lain, yaitu tes objektif. Meskipun demikian, tidak berarti bentuk esai ditinggalkan sama sekali. Bentuk esai dapat digunakan untuk mengukur kegiatan belajar yang sulit diukur oleh bentuk objektif. Dilihat dari luas sempitnya materi yang ditanyakan, maka tes bentuk esai atau bisa juga disebut uraian, dapat dibagi menjadi dua bentuk, yaitu uraian terbatas ( restricted respons items ) dan uraian bebas ( extented respons items ).

a. Uraian bebas artinya butir soal itu hanya menyangkut masalah utama yang dibicarakan tanpa memberikan arahan tertentu dalam menjawabnya.

Contoh : Allah telah melimpahkan nikmat-Nya kepada kita amat banyak. Oleh karena itu kita sudah sepatutnya mensyukuri nikmat tersebut kepada Allah SWT. Jelaskan bagaimana caranya kita mensyukuri nikmat Allah itu sesuai ajaran Rasulullah.

b. Uraian Terbatas artinya peserta didik diberi kebebasan untuk menjawab soal yang ditanyakan, namun arah jawaban dibatasi sedemikian rupa sehingga kebebasan tersbut menjadi bebas yang terarah.

Contoh : Dimasa Khulafaur Rasyidin, tercatat tiga peristiwa peperangan antara kaum muslimin menghadapi Romawi. Sebutkan dan Jelaskan secara singkat ketiga peristiwa dimaksud. 
2) Tes Objektif

Tes Objektif sering juga disebut tes dikotomi ( dichotomously scored item ) karena jawabannya antara benar atau salah dan skornya antara 1 atau 0 . Disebut tes objektif karena penilaiannya objektif. Siapapun yang mengoreksi jawaban tes ini maka hasilnya akan sama karena kunci jawabannya sudah jelas dan pasti. Tes objektif terdiri atas beberapa bentuk, yaitu benarsalah, pilihan ganda, menjodohkan, dan melengkapi jawaban atau jawaban singkat. Sebagaimana dikemukakan oleh Witherington ( 1952 ) bahwa, "There are many varietes of there new test, but four kinds are in most common use, true false, multiple-choice, completion, matching”.

a. Tes benar Salah

Tes benar salah adalah butir soal atau tugas yang berupa pernyataan yang jawabannya menggunakan pilihan pernyataan benar atau salah. Alternatif jawaban bisa berbentuk :

- Benar-salah

- Setuju-tidak setuju

- Baik-tidak baik

Contoh :

B-S : Penerjemahan Alqur'an dan sejumlah karya lain tidak berhenti memberikan sumbangan penting untuk kegiatan studi keislaman

B - S : Kota Toledo merupakan salah satu pusat ilmiah Islam Spanyol di Zaman Pertengahan Eropa

b. Tes Pilihan Ganda

Tes pilihan ganda ini umumnya terdiri atas kalimat pokok yang berupa pernyataan yang belum lengkap dan diikuti oleh empat sampai lima kemungkinan jawaban yang dapat melengkapi pernyataan tersebut. Pelajar harus memilih salah satu diantara kemungkinan jawaban tersebut. Contoh : Daulah Bani Abbasyah mencapai puncak kejayaan atau zaman keemasan pada masa pemerintahan :
a) Umar bin Abdul Aziz
b) Utsman bin Affan
c) Yazid bin Mu'awiyah
d) Harun Al-Rasyid 


\section{c. Tes Menjodohkan}

Tes menjodohkan ini sering dikenal dengan sebutan tes matching, tes mencari pasangan, tes menyesuaikan, tes mencocokkan, dan tes mempertandingkan. Jadi dalam tes ini disediakan dua kelompok bahan dan peserta didik harus mencari pasangan yang sesuai antara kelompok pertama dengan kelompok kedua sesuai petunjuk yang diberikan dalam tes tersebut.

Contoh :

\begin{tabular}{|c|l|l|}
\hline No & Daftar 1 & Daftar II \\
\hline 1 & Sholat sunah yang dilakukan pada tiap malam bulan ramadhan & Istikharah \\
\hline 2 & $\begin{array}{l}\text { Sholat sunah yang dilakukan untuk memohon petunjuk antara pilihan } \\
\text { yang akan ditentukan }\end{array}$ & Khauf \\
\hline 3 & $\begin{array}{l}\text { Sholat sunah yang dilakukan dalam keadaan takut atau dalam keadaan } \\
\text { bahaya }\end{array}$ & Tarawih \\
\hline
\end{tabular}

d. Tes Melengkapi jawaban atau jawaban singkat

Tes ini sering dikenal dengan tes completion, dimana tes ini berbentuk pernyataan yang salah satunya dikosongkan. Tugas peserta didik ialah mengisi jawaban pada kata-kata yang kosong tersebut.

Contoh :

- Aliran jabariyah terkenal dengan pahamnya...

- Lembaga keilmuan terkenal pada masa kejayaan khalifah al-Ma'mun bernama...

\section{Teknik Evaluasi Hasil Belajar}

Istilah "tehnik" dapat diartikan sebagai "alat". Jadi dalam istilah tehnik evaluasi hasil belajar terkandung arti alat-alat (yang dipergunakan dalam rangka melakukan) evaluasi hasil belajar. Secara garis besar ada dua kelompok tehnik evaluasi yang dapat digunakan oleh seorang guru dalam usahanya mencari informasi yang diperlukan. Kedua kelompok tersebut yaitu tes dan non tes. Pertama, tehnik evaluasi menggunakan cara tes, yang didalamnya berupa satu set atau lebih item pertanyaan atau pernyataan yang relevan dengan tujuan tes yang digunakan oleh seorang guru. Kedua, tehnik evaluasi yang juga banyak digunakan didalam kelas adalah tehnik evaluasi melalui nontes. Tes ini tidak menggunakan item pertanyaan atau pernyataan seperti disebutkan 
diatas, tetapi tes ini mengguanakan metode lain untuk memperoleh data atau informasi yang diperlukan.

Teknik evaluasi digolongkan menjadi 2 yaitu:

\section{Tehnik Tes}

\section{a. Pengertian Tes}

Istilah tes diambil dari kata testum suatu pengertian dalam bahasa perancis kuno yang berarti piring untuk untuk menyisihkan logam-logam mulia. Ada pula yang mengartikan sebagai sebuah piring yang terbuat dari tanah. Seorang ahli bernama James Ms.Cattel pada tahun 1890 telah memperkenalkan pengertian tes ini kepada masyarakat melalui bukunya yang berjudul Mental Test and Measurement. Selanjutnya di Amerika Serikat tes ini berkembang dengan cepat sehingga dalam tempo yang tidak begitu lama masyarakat mulai menggunakannya.

Adapun dari segi istilah, menurut Anne Anastasi dalam karya tulisnya berjudul Psychological Testing, yang dimaksud dengan tes adalah alat pengukur yang mempunyai standar yang obyektif sehingga dapat digunakan secara meluas, serta dapat betul-betul digunakan untuk mengukur dan membandingkan keadaan psikis atau tingkah laku individu. Adapun menurut Lee J. Cronbach dalam bukunya berjudul Esseintial of Psychological Testing, tes merupakan suatu prosedur yang sistematis untuk membandingkan tingkah laku dua orang atau lebih.

Sedangkan menurut Drs. Amir Daien Indrakusuma didalam bukunya yang berjudul Evaluasi Pendidikan mengatakan bahwa Tes adalh suatu alat atau prosedur yang sistematis dan objektif untuk memperoleh data-data atau keterangan-keterangan yang diinginkan tentang seseorang, dengan cara yang boleh dikatakan tepat dan cepat.

Dari definisi-definisi tersebut di atas kiranya dapat dipahami bahwa dalam dunia evaluasi pendidikan, yang dimaksud dengan tes adalah cara (yang dapat dipergunakan) atau prosedur (yang perlu ditempuh) dalam rangka pengukuran dan penilaian di bidang pendidikan, yang berbentuk pemberian tugas atau serangkaian tugas baik berupa pertanyaan-pertanyaan (yang harus dijawab), atau perintah-perintah (yang harus dikerjakan), sehingga atas dasar data yang diperoleh dari hasil pengukuran tersebut dapat dihasilkan nilai yang melambangkan tingkah laku atau prestasi, nilai mana dapat dibandingkan dengan nilai-nilai yang dicapai atau dibandingkan dengan nilai standar tertentu. 
b. Fungsi Tes

Secara umum ada dua macam fungsi yang dimiliki oleh tes, yaitu:

1) Sebagai alat pengukur terhadap peserta didik. Dalam hubungan ini tes berfungsi mengukur tingkat perkembangan atau kemajuan yang telah dicapai oleh peserta didik setelah mereka menempuh proses belajar mengajar dalam jangka waktu tertentu.

2) Sebagai alat pengukur keberhasilan program pengajaran, sebab melalui tes tersebut akan dapat diketahui sudah seberapa jauh program pengajaran yang telah ditentukan telah dapat dicapai. c. Penggolongan Tes

Sebagai alat pengukur, tes dapat dibedakan menjadi beberapa jenis atau golongan, tergantung dari segi mana atau dengan alasan apa penggolongan tes itu dilakukan.

1) Penggolongan tes berdasarkan fungsinya sebagai alat pengukur perkembangan/kemajuan belajar peserta didik.

Ditinjau dari segi fungsi yang dimiliki oleh tes sebagai alat pengukur perkembangan belajar peserta didik, tes dapat dibedakan menajadi enam golongan: 1) Tes Seleksi, 2) Tes Awal, 3) Tes Akhir, 4) Tes Diagnostik, 5) Tes Formatif, 6) Tes Sumatif.

a) Tes Seleksi

Tes seleksi sering dikenal dengan istilah "Ujian Saringan” atau "Ujian Masuk”. Tes ini dilakukan dalam rangka penerimaan calon siswa baru, dimana hasil tes digunakan untuk memilih calon peserta didik yang tergolong paling baik dari sekian banyak calon yang mengikuti tes.

b) Tes Awal

Tes awal sering dikenal dengan istilah pre-test. Tes jenis ini dilaksanakan dengan tujuan untuk mengetaui sejauh manakah materi atau bahan pelajaran yang akan diajarkan telah dapat dikuasai oleh para peserta didik. Jadi tes awal adalah tes yang dilaksanakan sebelum bahan pelajaran diberikan kepada peserta didik. Karena itu maka butir-butir soalnya dibuat yang mudahmudah.

c) Tes Akhir

Tes akhir sering dikenal dengan istilah post-test. Tes akhir dilaksanakan dengan tujuan untuk mengetahui apakah semua materi pelajaran yang tergolong penting sudah dapat dikuasai dengan sebaik-baiknya oleh para peserta didik. 


\section{d) Tes Diagnostik}

Tes diagnostik adalah tes yang dilaksanakan untuk menetukan secara tepat jenis kesukaran yang yang dihadapi oleh para peserta didik dalam suatu mata pelajaran tertentu. Dengan diketahuinya jenis-jenis kesukaran yang dihadapi oleh peserta didik itu maka lebih lanjut akan dapat dicarikan upaya berupa pengobatan (theraphy) yang tepat. Tes diagnostik juga bertujuan ingin menemukan jawab atas pertanyaan "Apakah peserta didik sudah dapat menguasai pengetahuan yang merupakan dasar atau landasan untuk dapat menerima pengetahuan selanjutnya?"

Materi yang ditanyakan dalam tes diagnostik pada umumnya ditekankan pada bahan-bahan tertentu yang biasanya atau menurut pengalaman sulit dipahami siswa. Tes jenis ini dapat dilaksanakan secara lisan, tertulis, perbuatan atau kombinasi dari ketiganya.

Sesuai dengan nama tes itu sendiri (diagnose=pemeriksaan), maka jika hasil pemeriksaan itu menunjukkan bahwa tingkat penguasaan peserta didik yang sedang diperiksa itu termasuk rendah maka harus diberi bimbingan secara khusus agar mereka dapat memperbaiki tingkat penguasaannyaterhadap mata pelajaran tertentu.

\section{KESIMPULAN}

Berdasarkan beberapa hasil pembahasan tersebut di atas maka dapat kami simpulkan sebagai berikut:

1. Bentuk evaluasi secara umum ada 2, yaitu subjektif dan objekti. Subjektif terbagi lagi menjadi 2 yaitu uraian bebas dan terbatas. Sedangkan objektif terbagi menjadi 4, yaitu pilihan ganda, benar-salah, menjodohkan, dan tes melengkapi jawaban.

2. Tes berdasarkan fungsinya teknik tes dibagi menjadi 6 , yaitu teknik seleksi, teknik awal, teknik akhir, teknik diagnostik, teknik formatif, dan teknik sumatif.

3. Tes berdasarkan aspek psikisnya dibagi menjadi 4, yaitu : teknik intelegensi, kemampuan, kepribadian, dan prestasi hasil belajar

4. Berdasarkan jumlah peserta didiknya dibagi menjadi 2 yaitu : teknik individual dan teknik kelompok

5. Berdasarkan pertanyaannya dibagi menjadi 2 juga yaitu : teknik tertulis dan teknik lisan

6. Sedangkan untuk teknik non tes dibagi menjadi 4, yaitu : pengamatan, wawancara, angket dan pemeriksaan dokumen. 


\section{DAFTAR PUSTAKA}

Halwa, H., \& Arsyam, M. CIRI-CIRI, PRINSIP-PRINSIP, JENIS DAN PROSES EVALUASI PENDIDIKAN.

Ramadani, W., Dahri, M., \& Arsyam, M. (2021, January 17). ADMINITRASI KEMITRAAN SEKOLAH DENGAN MASYAKARAT. https://doi.org/10.31219/osf.io/fpm9u

Arsi, A., Arsyam, M., \& Irma, I. administrasi tata kelola dalam pendidikan.

Djemari Mardapi. (2008). Teknik penyusunan instrumen tes dan non tes. Yogyakarta: Mitra Cendekia

Arsi, A., \& Arsyam, M. (2021). Administrasi Tata Kelola Dalam Pendidikan.

Nana Sudjana, Ibrahim, 2007,Penelitian dan Penilaian Pendidikan, Sinar Baru Algesindo,

Ramadani, W., Dahri, M., \& Arsyam, M. (2021). ADMINITRASI KEMITRAAN SEKOLAH DENGAN MASYAKARAT.

Neta, Y. (2014). Model Tata Kelola Administrasi Pemerintahan Yang Baik di Daerah Otonom Baru. FIAT JUSTISIA: Jurnal Ilmu Hukum, 6(2).

Fajrin, M. F., Rifqi, N., \& Arsyam, M. (2021). ADMINISTRASI KESISWAAN DALAM PENDIDIKAN.

Hardiansyah, H., \& Fahmi, A. (2018, September). Strategi Tata Kelola Administrasi Pada Perguruan Tinggi Berbasis Electronic Records. In Prosiding Seminar Nasional Lembaga Penelitian Dan Pendidikan (LPP) Mandala (pp. 246-250).

Janna, N. M., \& Arsyam, M. (2021). administrasi Keuangan dalam Pendidikan.

Mulyasa, Endang. 2007. Manajemen Berbasis Sekolah. Bandung: PT Remaja Rosdakarya.

Arsyam, M. (2020). Manajemen pendidikan islam.

Kristiawan, M., \& Asvio, N. (2018). Pengelolaan Administrasi Madrasah Tsanawiyah Negeri Dalam Meningkatkan Kualitas Pendidikan Madrasah. Kelola: Jurnal Manajemen Pendidikan, 5(1), 86-95.

Dahri, M., Ramadani, W., \& Arsyam, M. (2021). ADMINISTRASI EVALUASI DAN PENILAIAN DALAM PENDIDIKAN.

Griffin, P. \& Nix, P. (1991). Educational Assessment and Reporting. Sydney: Harcout Brace Javanovich, Publisher.

SUPANDI, S., Khadijah, K., \& Arsyam, M. (2021). Tes standar dan tes non standar.

Undang-Undang Nomor 20 Tahun 2003 tentang Sistem Pendidikan Nasional. http//www.evaluasipendidikan.blogspot.com.

Ramadhani, W. S., Murti, M., \& Arsyam, M. (2021). TEKNIK PENGOLAHAN SKOR HASIL EVALUASI.

Farida Yusuf Tayibnapis. (2000). Evaluasi Program. Jakarta: Rineka Cipta

Arsyam, M., Jumliadi, M. H., \& Alwi, A. M. S. (2020). PEMBELAJARAN DIRUMAH DALAM LINGKUNGAN KELUARGA DI TENGAH PANDEMI COVID 19. 
Astuti, S. (2016). Penerapan supervisi akademik untuk meningkatkan kompetensi guru dalam menyusun administrasi penilaian di sd laboratorium uksw. Scholaria: Jurnal Pendidikan dan Kebudayaan, 6(1), 117-126.

Arsyam, M. (2021). BAHAN AJAR ADMINISTRASI PENDIDIKAN.

Zakirah, Z., Jumliadi, J., Arsyam, M., Herianto, H., Rusli, M., \& Alwi, A. M. Implementation of The Islamic Local Regulations in Bulukumba Regency.

Anas Sudijono (1998) Pengantar Evaluasi Pendidikan, Jakarta ; P>T. Raja Grafindo Persada

Zakirah, Z., Arsyam, M., HERIANTO, H., \& Umar, K. (2020, December 20). PENDIDIKAN DASAR (KUTTAB) MASA DAULAH ABBASIYAH $(132-232 \quad \mathrm{H} \quad / \quad 750-847 \quad \mathrm{M})$. https://doi.org/10.31219/osf.io/7t8bs

Makmur, Z., Arsyam, M., \& Alwi, A. M. S. (2020). Strategi Komunikasi Pembelajaran Di Rumah Dalam Lingkungan Keluarga Masa Pandemi. KOMUNIDA: Media Komunikasi dan Dakwah, 10(02), 231241. 